\title{
Listeria monocytogenes: monitoramento desse perigo biológico na cadeia produtiva de frangos do sul do Rio Grande do Sul
}

\author{
Listeria monocytogenes: assessing this microbiological hazard in a \\ poultry productive chain in southern Rio Grande do Sul
}

\author{
Élen Silveira NALÉRIO ${ }^{1}$, Márcia Ribeiro de ARAÚJO ${ }^{1}$, \\ Karla Sequeira MENDONÇA ${ }^{1}$, Milena Tomasi BASSANI ${ }^{1}$, Wladimir Padilha da SILVA ${ }^{1 *}$
}

\section{Resumo}

Listeria monocytogenes é uma bactéria patogênica que se tornou um grande desafio para as indústrias de alimentos, entre elas a de frangos, assim como para os órgãos de vigilância sanitária. Apesar da produção de frangos estar em expansão na região sul do Rio Grande do Sul, não há relatos sobre esse patógeno, dessa forma, objetivou-se avaliar a prevalência de L. monocytogenes e de seus sorotipos nos diversos segmentos dessa cadeia produtiva. Nos aviários isolou-se L. monocytogenes em 2,9\% (1/35) das amostras de swabs cloacais, não se isolando o microrganismo em amostras provenientes das camas de aviários. No abatedouro, 11,7\% (15/128) das amostras apresentaram contaminação por L. monocytogenes e nos frangos resfriados procedentes do comércio, a prevalência foi de 33,3\% (15/45). Observou-se que 51,6\% (16/31) das cepas de L. monocytogenes pertenciam ao sorotipo $1 / 2 \mathrm{~b} ; 22,5 \%$ (7/31) ao sorotipo $4 \mathrm{e} ; 16,1 \%(5 / 31)$ ao sorotipo $1 / 2 \mathrm{a} ; 6,4 \%$ (2/31) ao sorotipo 4b; e 3,2\% (1/31) ao sorotipo 1/2c. Há disseminação de L. monocytogenes na cadeia produtiva de frangos da região sul do Rio Grande do Sul e a presença de sorotipos prevalentes em casos/surtos de listeriose traz preocupação à saúde pública.

Palavras-chave: Listeria monocytogenes; Listeria spp.; estabelecimentos avícolas; abatedouro; frangos resfriados.

\begin{abstract}
Listeria monocytogenes is a pathogenic bacterium which has become a huge challenge to the food industries, including the poultry industry, and to the health surveillance agencies. Although poultry production is in expansion in southern of Rio Grande do Sul, Brazil, there are not reports about this pathogen thus this study aimed at assessing the prevalence of $L$ monocytogenes and its serotypes in the several segments of this productive chain. In the broilers flocks L. monocytogenes were isolated in $2.9 \%$ (1/35) from cloacal swabs samples. This microorganism was not isolated from broiler houses samples. In the abattoir, $11 \%$ of the samples presented L. monocytogenes contamination, and in the chilled chicken from retailers its prevalence was $33.3 \%$ (15/45). It was observed that $51.6 \%(16 / 31)$ from $L$. monocytogenes strains belonged to serotype $1 / 2 \mathrm{~b}, 22.5 \%(7 / 31)$ to serotype $4 \mathrm{e}, 16,1 \%(5 / 31)$ to serotype $1 / 2 \mathrm{a}, 6,4 \%(2 / 31)$ to serotype $4 \mathrm{~b}$, and $3,2 \%(1 / 31)$ to serotype $1 / 2 \mathrm{c}$. The spread of L. monocytogenes in the poultry production chain in southern Rio Grande do Sul and the presence of poultry serotypes in cases/outbreaks of listeriosis cause concern to public health.
\end{abstract}

Keywords: Listeria monocytogenes; Listeria spp.; poultry establishments; slaughterhouse; chilled chicken.

\section{Introdução}

L. monocytogenes é o agente etiológico da listeriose, uma infecção grave, veiculada principalmente por alimentos, que ocasiona encefalites, septicemias, meningites e abortos (DUSSURGET; PIZARRO-CERDA; COSSART, 2004). Pertence ao gênero Listeria, composto por seis espécies que se apresentam amplamente distribuídas no ambiente (CDC, 2005) devido às suas características fisiológicas peculiares, que as capacitam a sobreviver e a se multiplicar sob condições adversas a muitos outros microrganismos (GRAVESEN et al., 2000; UHITIL et al., 2004). L. monocytogenes é a principal espécie de Listeria envolvida em doenças em humanos (ROUCOURT; SEELIGER, 1985; FARBER; PETERKIN, 1991), entretanto, as outras espécies são importantes por apresentarem ecologia semelhante à deste patógeno, podendo ser consideradas indicadoras de sua presença (DELGADO et al., 1998; VITAS, AGUADO; GARCIA-JALON 2004).

Um importante aspecto a ser considerado nas indústrias de alimentos é o fato de existirem cepas de L. monocytogenes persistentes, as quais são capazes de permanecer meses, ou até anos, no ambiente de processamento, podendo assim provocar contaminações recorrentes no produto final (MARKKULA et al., 2005). A dificuldade em eliminar esse microrganismo das indústrias é potencializada pelas condições de umidade, temperatura e presença de matéria orgânica nas plantas de processamento, que aliadas à habilidade do patógeno em produzir biofilmes, podem desencadear a colonização de superfícies de equipamentos e utensílios (UHITIL et al., 2004).

Recebido para publicação em 13/12/2007

Aceito para publicação em 18/9/2008 (003093)

1 Programa de Pós-Graduação em Ciência e Tecnologia Agroindustrial, Departamento de Ciência e Tecnologia de Alimentos, Faculdade de Agronomia Eliseu Maciel,

Universidade Federal de Pelotas - UFPel, Campus Universitário, s/n, CP 354, CEP 96010-900, Pelotas - RS, Brasil, E-mail: silvawp@ufpel.edu.br

${ }^{*}$ A quem a correspondência deve ser enviada 
As diversas etapas envolvidas na produção, processamento e armazenamento de frangos podem ser importantes fontes de contaminação por L. monocytogenes (BARBALHO et al., 2005; MIETTINEM et al., 2001), sendo relevante investigar e compreender a dispersão desse microrganismo na cadeia produtiva desse tipo de alimento, de forma a estabelecer estratégias adequadas para seu controle. Além disso, a produção de frangos na região sul do Rio Grande do Sul está em expansão, e com isso torna-se pertinente avaliar a prevalência de L. monocytogenes nessa cadeia produtiva, haja vista que inexistem dados disponíveis na literatura acerca desse microrganismo nessa região geográfica. Portanto, investigações epidemiológicas, tais como a proposta neste estudo, são ferramentas importantes para a determinação de perigos e o posterior estudo dos riscos associados a esse alimento.

A partir do exposto, objetivou-se verificar a prevalência de L. monocytogenes e de seus sorotipos na cadeia produtiva de frangos da região sul do Rio Grande do Sul.

\section{Material e métodos}

\subsection{Coleta de amostras}

Foram coletadas amostras em 35 estabelecimentos avícolas (aviários) e em um abatedouro de frangos localizados na região sul do Rio Grande do Sul, bem como de frangos refrigerados comercializados na mesma região. Todos os pontos de amostragem estão descritos na Tabela 1. Após a obtenção das amostras, essas foram acondicionadas em caixas isotérmicas contendo gelo e transportadas para o Laboratório de Microbiologia de Alimentos, no Departamento de Ciência e Tecnologia Agroindustrial, da Faculdade de Agronomia Eliseu Maciel, na Universidade Federal de Pelotas, onde foram submetidas à análise microbiológica.

\section{Estabelecimentos avícolas (aviários)}

As amostras foram coletadas em 35 aviários localizados em cinco municípios da região sul do Rio Grande do Sul, utilizandose swabs de arrasto das camas de aviários (35) e swabs das cloacas das aves (35), totalizando 70 amostras. Para a coleta de swabs de arrasto utilizou-se o protocolo para controle de Salmonella spp., preconizado pelo Programa Nacional de Sanidade Avícola PNSA Portaria $n^{\circ} 193$ (BRASIL, 1994) do MAPA (Ministério da Agricultura Pecuária e Abastecimento) e pela Portaria n ${ }^{\circ} 126$ (BRASIL, 1995), com algumas modificações, onde cada swab de arrasto representava um aviário. A presença de L. monocytogenes no trato intestinal das aves foi avaliada por swabs cloacais, onde cada amostra representava um aviário, sendo formada por um pool de oito aves. Imediatamente após a coleta, os swabs foram imersos em frascos contendo solução salina $0,85 \%$, estéril, e transportados para o laboratório para o processamento das amostras.

\section{Abatedouro}

Foi realizada uma coleta por mês, durante quatro meses, em um abatedouro comercial de frangos localizado na região sul do Rio Grande do Sul. Todos os procedimentos de amostragem foram executados conforme o protocolo proposto por Ryser e Donnelly (2001). Coletaram-se 128 amostras, sendo 84 referentes a frangos/carcaças, 24 amostras de superfícies que

Tabela 1. Pontos de amostragem e distribuição de sorotipos de L. monocytogenes na cadeia produtiva de frangos do sul do Rio Grande do Sul.

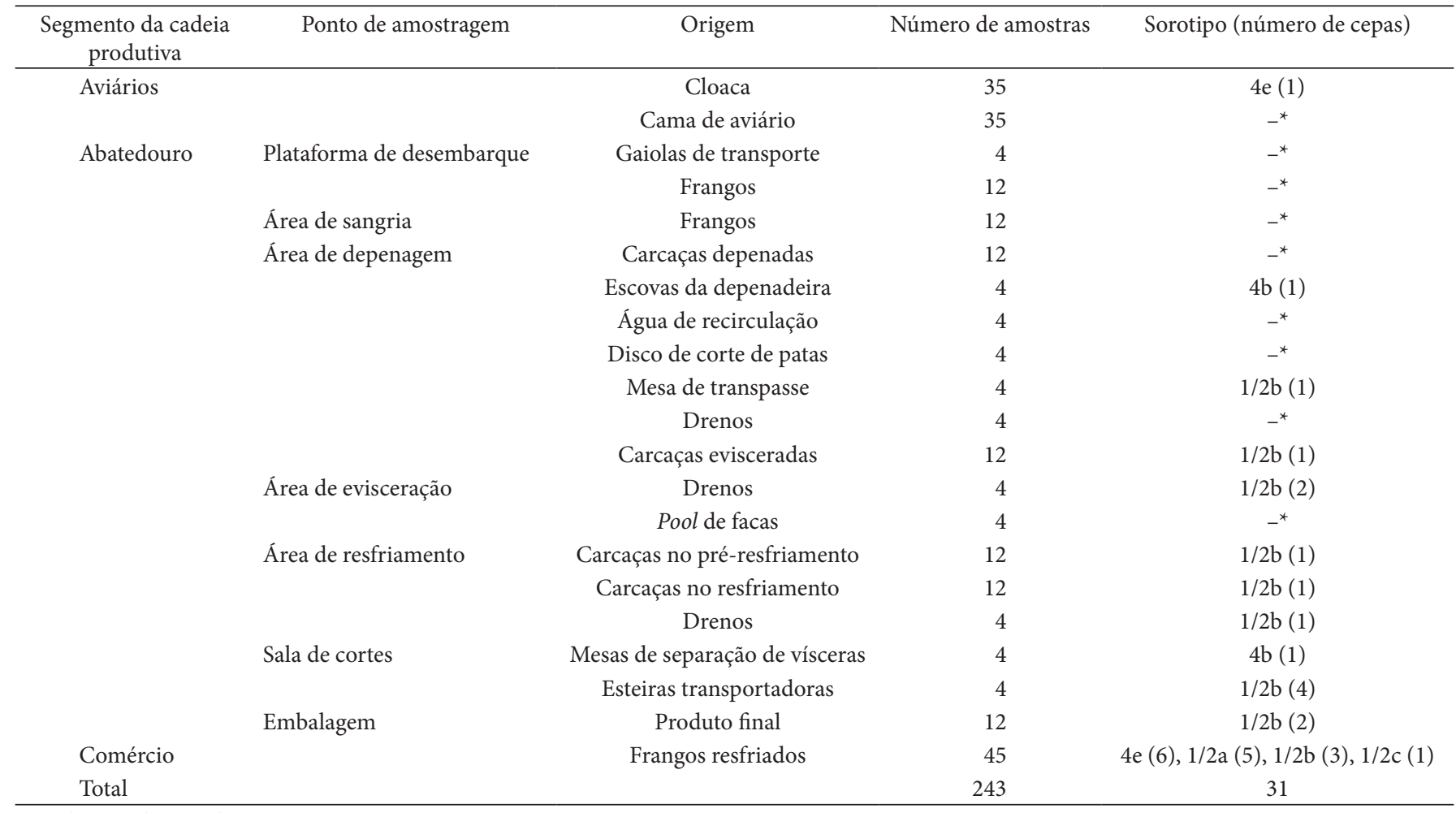

\footnotetext{
*Não houve isolamento de L. monocytogenes.
} 
entram em contato com o alimento e 20 de superfícies que não mantêm contato com o alimento.

As amostras de frangos/carcaças foram coletadas em três diferentes fases do abate: no início, na etapa intermediária e ao final do abate, de forma a minimizar a influência do horário de coleta sobre os resultados. Em cada uma dessas fases, cinco frangos foram escolhidos aleatoriamente na plataforma de desembarque, marcados com lacres de diferentes cores, acompanhados e avaliados ao longo da linha de abate. Em cada fase do abate formaram-se amostras compostas com o pool dos cinco frangos/carcaças por ponto de amostragem, totalizando três amostras por ponto em cada coleta. A amostragem da superfície (penas, pele e cloaca) nos frangos na plataforma de desembarque foi realizada com swabs esterilizados umedecidos em solução salina 0,85\% e armazenados em caldo de Enriquecimento para Listeria - LEB (LEB UVM - 1, Oxoid ${ }^{\circ}$ ) adicionado do suplemento SR141E (Oxoid'), no momento em que as aves foram retiradas das caixas plásticas de transporte e penduradas na nórea. Na linha de abate, a amostragem foi realizada pela técnica de lavagem superficial, em sacos plásticos estéreis contendo $225 \mathrm{~mL}$ de água peptonada $0,1 \%$ e, imediatamente após a chegada ao laboratório, retiravam-se alíquotas de $25 \mathrm{~mL}$, que foram inoculadas em $225 \mathrm{~mL}$ de LEB e incubadas a $30^{\circ} \mathrm{C}$ durante 24 horas.

As superfícies amostradas, que entram em contato com o alimento, foram as escovas da depenadeira, as mesas utilizadas para separação de vísceras, o disco de corte de patas, as facas usadas na evisceração, o estrado da mesa de transpasse e as esteiras transportadoras. As superfícies avaliadas que não entram em contato com o alimento foram as caixas plásticas em que os frangos estavam sendo transportados até a indústria, os drenos das áreas de evisceração e de resfriamento e a água de recirculação da área de depenagem. Todas as amostragens foram realizadas imediatamente antes do início das atividades, através de swabs esterilizados umedecidos em solução salina 0,85\% e transportados em LEB.

\section{Frangos resfriados provenientes do comércio}

Foram avaliadas 45 amostras de frangos resfriados coletadas no comércio, e os procedimentos de amostragem foram realizados de acordo com Ryser e Donnelly (2001).

Utilizou-se a técnica de lavagem superficial, em sacos plásticos estéreis contendo $225 \mathrm{~mL}$ de água peptonada $0,1 \%$ e, em seguida, retiraram-se alíquotas de $25 \mathrm{~mL}$, que foram inoculadas em $225 \mathrm{~mL}$ de $\mathrm{LEB}$, e incubadas a $30{ }^{\circ} \mathrm{C}$ durante 24 horas.

\subsection{Isolamento, identificação de Listeria spp.e sorotipificação das cepas de Listeria monocytogenes}

O isolamento e a identificação de Listeria em nível de espécie foram realizados de acordo com protocolo descrito por Farber et al. (1994).

Após a identificação, todas as cepas de L. monocytogenes foram cultivadas em tubos tipo Eppendorf contendo ágar Soja Triptona (TSA - Acumedia ${ }^{\circledR}$ enriquecido com Extrato de Levedura $0,6 \%$ (TSA-YE), incubadas a $35-37{ }^{\circ} \mathrm{C}$ durante 24 horas e, posteriormente, encaminhadas para o Laboratório de Zoonoses Bacterianas do Departamento de Bacteriologia do Instituto Oswaldo Cruz - FIOCRUZ, RJ, para serem submetidas à sorotipificação.

\section{Resultados e discussão}

A produção de frangos está em constante expansão na região sul do Rio Grande do Sul e, apesar de L. monocytogenes ser um patógeno de grande importância para a saúde pública, e que pode ser veiculado por frangos e derivados, o Programa de Redução de Patógenos do MAPA (BRASIL, 1994) não prevê seu monitoramento. Dessa forma, os resultados obtidos neste estudo, que avaliou os diferentes segmentos da cadeia produtiva de frangos nessa região geográfica, trazem importantes subsídios para implantação de sistemas de gerenciamento visando o controle desse microrganismo.

A prevalência de Listeria spp. foi de 38,3\% (93/243), com $30,4 \%(74 / 243)$ das amostras positivas para L. innocua, $12,7 \%$ (31/243) para L. monocytogenes e 0,4\% (1/243) para L. seeligeri. Esses resultados são importantes, pois, embora L. monocytogenes seja a principal espécie patogênica para humanos, a identificação das outras espécies é um bom indicador da sua presença em alimentos e em plantas de processamento, além de refletir procedimentos de sanitização inadequados.

Verificou-se que 2,9\% (1/35) das amostras de swab cloacal estavam contaminadas com L. monocytogenes e que nas amostras provenientes de cama de aviário esse microrganismo não foi isolado. Esse resultado é semelhante ao obtido por Petersen e Madsen (2000), que isolaram L. monocytogenes em 3\% das amostras de fezes de frangos, entretanto, Ojeniyi et al. (1996), bem como Fenlon et al. (1996), não isolaram esse microrganismo em amostras de ceco nem de fezes de frangos, respectivamente. São escassos os relatos disponíveis na literatura sobre a presença de L. monocytogenes no trato intestinal de frangos de corte, o que dificulta a discussão dos dados obtidos. De qualquer maneira, verificou-se que há frangos de corte portadores desse patógeno na região avaliada, possibilitando a contaminação dos criatórios e dos abatedouros e podendo, assim, atuar como uma fonte de introdução de cepas na linha de abate.

Entre as amostras provenientes do abatedouro, observouse que $11,7 \%(15 / 128)$ apresentavam contaminação por L. monocytogenes. Diversas pesquisas têm sido delineadas no mundo todo, com o objetivo de verificar e mapear os pontos de contaminação por L. monocytogenes em plantas de abate/processamento de aves, as quais demonstram taxas de isolamento bastante discrepantes (MIETTINEN et al., 2001; LÚNDEN et al., 2003; GUDBJORNSDÓTTIR et al., 2004). O mesmo se verifica quando se compara os dados obtidos neste estudo com outras pesquisas realizadas no Brasil. Chiarini (2007) avaliou duas plantas de processamento de aves no interior de São Paulo e encontrou ocorrência de 20,1\% em abatedouros com evisceração automática e $16,4 \%$ naqueles com evisceração manual, e Reiter et al. (2005) encontraram o patógeno em $35,6 \%$ das amostras provenientes de uma linha de abatedouro de aves no Rio Grande do Sul. É interessante frisar que embora 
as coletas tenham sido realizadas em três fases do processo de abate (início, fase intermediária e fase final do abate), não houve diferença na taxa de isolamento de L. monocytogenes entre as distintas fases (dados não mostrados), contrapondo ao descrito por Whyte et al. (2004), que encontraram grande interferência do horário de amostragem durante o abate de frangos sobre a frequência de amostras positivas para esse microrganismo.

L. monocytogenes foi isolada em diversos pontos da planta de abate, como escovas da depenadeira, mesa de transpasse, dreno da área de evisceração, dreno da área de resfriamento, mesa de separação de vísceras e esteiras transportadoras, bem como das carcaças na evisceração, pré-resfriamento, resfriamento e produto final (Tabela 1). $\mathrm{O}$ fato de não ter havido isolamento de L. monocytogenes nas aves que entraram na planta de processamento (plataforma de desembarque e sangria), com posterior presença do patógeno no produto final, demonstra a dispersão desse microrganismo e, portanto, a importância da contaminação cruzada dentro dessa indústria, fato corroborado pelo frequente número de pontos em que esse microrganismo foi isolado e pela prevalência de apenas dois sorotipos (1/2b e $4 \mathrm{~b}$ ) nas amostras provenientes do abatedouro. Pode-se observar pela Tabela 1, que à medida que o processamento progride, aumenta a taxa de contaminação por L. monocytogenes, o que também foi relatado por Reiter et al. (2005), os quais descrevem que a contaminação das carcaças ocorre principalmente durante ou após as etapas de evisceração e resfriamento, e por Barbalho et al. (2005), que avaliaram um abatedouro de frangos na Bahia e encontraram L. monocytogenes em $14,3 \%$ das carcaças já embaladas, as quais não estavam contaminadas nas etapas anteriores.

Considerando-se apenas as amostras representativas das superfícies que entram em contato com o alimento (escovas da depenadeira, mesas de separação de vísceras, disco de corte de patas, facas usadas na evisceração, mesa de transpasse, esteiras transportadoras) a prevalência de L. monocytogenes foi de $29,2 \%$ (7/24), ao passo que a contaminação nas amostras que não mantêm contato com o alimento (caixas plásticas para transporte, drenos das áreas de evisceração e de resfriamento e a água de recirculação da sala de depenagem), foi de 15\% (3/20) (Tabela 1). Resultados semelhantes foram obtidos por Chiarini (2007), que avaliou duas indústrias de processamento de frangos do interior de São Paulo e encontrou $23,4 \%$ de contaminação por esse microrganismo em superfícies que entram em contato com o alimento, e 16,8\% em superfícies que não mantêm contato com o alimento.

A prevalência de L. monocytogenes em frangos resfriados comercializados na região estudada foi de 33,3\% (15/45). Elevados níveis de contaminação nesse tipo de alimento também foram descritos por outros autores, como Miettinen et al. (2001), que avaliaram a presença de L. monocytogenes em cortes de frango procedentes do comércio finlandês e encontraram $62 \%$ de contaminação, assim como Vitas, Aguado e Garcia-Jalon (2004), que encontraram essa bactéria em $36,1 \%$ das amostras, na Espanha. A elevada prevalência do patógeno nos produtos procedentes do comércio reflete a grande distribuição desse microrganismo dentro das indústrias, como pôde ser observado neste estudo, bem como a dificuldade de sua eliminação do ambiente das plantas de abate/processamento de aves.
Todas as cepas de L. monocytogenes são consideradas patogênicas ao homem, entretanto, há diferenças entre elas no potencial de virulência. Um fato que demonstra essa diferença é que, embora esse microrganismo apresente 13 sorotipos, mais de $95 \%$ dos surtos e casos esporádicos de listeriose que ocorrem no mundo são causados por cepas de três sorotipos: 4b, 1/2a e 1/2b (JACQUET et al., 2002; JESÚS; WHITING, 2003; LIANOU et al., 2006). Neste estudo observou-se que 51,6\% (16/31) das cepas pertenciam ao sorotipo $1 / 2 \mathrm{~b} ; 22,5 \%(7 / 31)$ ao sorotipo 4e; $16,1 \%(5 / 31)$ ao sorotipo $1 / 2 \mathrm{a} ; 6,4 \%(2 / 31)$ ao sorotipo $4 \mathrm{~b}$; e $3,2 \%(1 / 31)$ ao sorotipo $1 / 2$ c, portanto, mais de $70 \%$ das cepas pertenciam a sorotipos prevalentes em listeriose humana.

Todas as cepas isoladas no abatedouro pertenciam aos sorotipos $1 / 2 \mathrm{~b}$ e $4 \mathrm{~b}$, havendo prevalência do primeiro, com $86,6 \%(13 / 15)$, o que demonstra a dispersão do patógeno na indústria avaliada. Já nas amostras de frangos resfriados provenientes do comércio local também foram obtidas 15 cepas, entretanto, observou-se uma grande diversidade entre os sorotipos, com $40 \%$ das cepas pertencendo ao sorotipo 4e; $33,3 \%$ ao $1 / 2$ a; $20 \%$ ao $1 / 2$ b; e $6,6 \%$ ao $1 / 2$ c. Salienta-se que nem todas as amostras de frangos resfriados foram provenientes do abatedouro avaliado, o que pode ter contribuído para essa diversificação nos sorotipos obtidos.

Um resultado importante, que demonstra a dispersão de L. monocytogenes na cadeia produtiva avaliada, foi a presença de aves portadoras de cepas pertencentes ao sorotipo $4 \mathrm{e}$ e o posterior isolamento, e prevalência, desse sorotipo nos frangos resfriados no comércio. Apesar de cepas 4e não terem sido isoladas no abatedouro, $40 \%$ (6/15) das cepas provenientes dos frangos resfriados pertenciam a esse sorotipo. É interessante frisar que embora tenham sido coletadas amostras de diferentes marcas comerciais processadas em outras regiões do estado, com a finalidade de comparar os sorotipos prevalentes (dados não mostrados), todas as cepas $4 \mathrm{e}$ foram isoladas a partir de frangos processados no abatedouro avaliado, o qual recebia as aves dos aviários que foram amostrados neste estudo. Esse resultado também sugere que as cepas do sorotipo 4e isoladas neste estudo têm pouca capacidade de persistir no ambiente de processamento, ao contrário das cepas $1 / 2 \mathrm{~b}$ e $4 \mathrm{~b}$, o que corrobora a afirmação de outros autores, como Lunden et al. (2000), que destacam a existência de cepas de L. monocytogenes que são dominantes e que aderem melhor às superfícies de contato, o que lhes possibilita a permanência por longos períodos no ambiente da indústria.

Em alimentos com atividade de água e valores de $\mathrm{pH}$ adequados ao crescimento microbiano (tais como a carne de frango), estocados sob refrigeração, a temperatura exerce uma pressão seletiva sobre a microbiota presente, favorecendo a multiplicação de microrganismos psicrotróficos, como L. monocytogenes (RYSER; MARTH, 1999). Embora esses alimentos sofram tratamento térmico antes do consumo, e L. monocytogenes seja destruída pelo aquecimento adequado, sua manipulação nos restaurantes e domicílios pode ser uma importante fonte de contaminação cruzada desse patógeno para alimentos prontos para o consumo (HUSS; JORGENSEN; VOGEL, 2000; GUDBJORNSDÓTTIR et al., 2004). 
Na região avaliada não há registro de listeriose em humanos, entretanto, a prevalência de $L$. monocytogenes encontrada neste estudo, bem como a presença dos principais sorotipos envolvidos em casos e surtos de listeriose, demonstra que L. monocytogenes é um perigo biológico importante, em especial para determinados grupos da população considerados "de risco", como imunocomprometidos, gestantes e idosos. Esses resultados servem de suporte para o desenvolvimento de estratégias que visem o controle da bactéria em nível de indústria, bem como permitem o incremento do conhecimento acerca desse patógeno na região de estudo, de forma a prevenir a ocorrência de listeriose.

\section{Conclusões}

Há presença de L. monocytogenes em todos os elos da cadeia produtiva de frangos da região sul do Rio Grande do Sul e, embora haja diversidade entre os sorotipos isolados, $1 / 2$ be o mais prevalente, o que, dada sua importância epidemiológica, denota preocupação do ponto de vista de saúde pública. Além disso, ocorre dispersão de L. monocytogenes na planta de abate avaliada, favorecendo a contaminação cruzada do produto final.

\section{Agradecimentos}

À Fundação Coordenação de Aperfeiçoamento de Pessoal de Nível Superior (CAPES) pela concessão da bolsa de demanda social e ao Prof. Dr. Ernesto Hoffer, do Laboratório de Zoonoses Bacterianas do Departamento de Bacteriologia do Instituto Oswaldo Cruz (FIOCRUZ), pela sorotipificação dos isolados.

\section{Referências bibliográficas}

BARBALHO, T. C. F. et al. Prevalence of Listeria spp. at a poultry processing plant in Brazil and a phage test for a rapid test confirmation of suspect colonies. Food Control, v. 16, n. 3, p. 211-216, 2005.

BRASIL. Secretaria de Defesa Agropecuária. Portaria Ministerial no 193, de 19 de Setembro de 1994. Programa Nacional de Sanidade Avícola (PNSA). Disponível em: <http://extranet.agricultura.gov. br/sislegis-consulta>. Acesso em: Outubro 2006.

BRASIL. Secretaria de Defesa Agropecuária. Portaria n ${ }^{\circ}$ 126, de 3 de Novembro de 1995. Normas de credenciamento e monitoramento de laboratórios de diagnóstico das salmoneloses aviárias ( $S$. Enteritidis, $S$. Gallinarum, S. Pullorum e S. Typhimurium). Disponível em: $<$ http://extranet.agricultura.gov.br/sislegis-consulta $>$. Acesso em: Outubro 2006.

Center for Disease Control and Prevention - CDC. Listeriosis. In: . Division of bacterial and mycotic disease. Disponível em: <http://www.cdc.gov/ncidod/dbmd/diseaseinfo/listeriosis_g. htm $>$. Acesso em: Janeiro 2006.

CHIARINI, E. Listeria monocytogenes em matadouros de aves: marcadores sorológicos e genéticos no monitoramento de sua disseminação. São Paulo, 2007. p. 141 Tese (Doutorado em Ciência dos Alimentos) - Universidade de São Paulo - USP.

DELGADO, M. C.; HOFER, E.; TIBANA, A. Incidence of Listeria monocytogenes in cheese produced in Rio de Janeiro, Brazil. Journal of Food Protection, v. 61, n. 3, p. 354-356, 1998.

DUSSURGET, O.; PIZARRO-CERDA, J.; COSSART, P. Molecular determinants of Listeria monocytogenes virulence. Annual Review of Microbiology, v. 58, p. 587-610, 2004.

FARBER, J. M.; PETERKIN, P. I. Listeria monocytogenes, a foodborne pathogen. Microbiology Review, v. 55, n. 3, p. 476-511, 1991.

FARBER, J. M.; WARBURTON, D. W.; BABIUK, T. Isolation of Listeria monocytogenes from all food and environmental samples.
Government of Canada - HPB Method. Quebec (Canadá): Polyscience Publications, Sep. 1994.

FENLON, D. R.; WILSON, J.; DONACHIE, W. The incidence and level of Listeria monocytogenes contamination of food sources at primary production and initial processing. Journal of Applied Bacteriology, v. 81, n. 6, p. 641-650, 1996.

GRAVESEN, A. et al. Genotyping of Listeria monocytogenes: comparison of RAPD, ITS, and PFGE. International Journal of Food Microbiology, v. 57, n. 1-2, p. 43-51, 2000.

GUDBJORNSDÓTTIR, B. et al. The incidence Listeria monocytogenes in meat, poultry, and seafood plants in the Nordic countries. Food Microbiology, v. 21, n. 2, p. 217-225, 2004.

HUSS, H. H.; JORGENSEN, L. V.; VOGEL, B. F. Control options for Listeria monocytogenes in seafoods. International Journal of Food Microbiology, v. 62, n. 3, p. 267-274, 2000.

JACQUET, C. et al. Expression of ActA, Ami, InlB, and Listeriolysin O in Listeria monocytogenes of human and food origin. Applied and Environmental Microbiology, v. 68, n. 2, p. 616-622, 2002.

JESÚS, A. J.; WHITING, R. C. Thermal inactivation, growth, and survival studies of Listeria monocytogenes strains belonging to three distinct genotypic lineages. Journal of Food Protection, v. 66, n. 9, p. 1611-1617, 2003.

LIANOU, A. et al. Growth and stress resistance variation in culture broth among Listeria monocytogenes strains of various serotypes and origins. Journal of Food Protection, v. 69, n. 11, p. 2640-2647, 2006.

LUNDEN, J. M. et al. Persistent and nonpersistent Listeria monocytogenes contamination in meat and poultry processing plants. Journal of Food Protection, v. 66, n. 11, p. 2062-2069, 2003.

LUNDEN, J. M. et al. Persistent Listeria monocytogenes strains show enhanced adherence to food contact surface after short contact times. Journal of Food Protection, v. 63, n. 9, p. 1204-1207, 2000.

MARKKULA, A. et al. Raw and processed fish show identical Listeria monocytogenes genotypes with pulsed-field gel eletrophoresis. Journal of Food Protection, v. 68, n. 6, p. 1228-1231, 2005.

MIETTINEM, M. K. et al. Prevalence of Listeria monocytogenes in broilers at the abattoir, processing plant, and retail level. Journal of Food Protection, v. 64, n. 7, p. 994-999, 2001.

OJENIYI, B. et al. Listeria monocytogenes in poultry and poultry products: epidemiological investigations in seven Danish abattoirs. Journal of Applied Bacteriology, v. 80, n. 4, p. 395-401, 1996.

PETERSEN, L.; MADSEN, M. Listeria spp. in broiler flocks: recovery rates and species distribution investigated by conventional culture and the EiaFoss method. International Journal of Food Microbiology, v. 58, n.1-2, p.113-116, 2000.

REITER, M. G. R. et al. Occurrence of Campylobacter and Listeria monocytogenes in a poultry processing plant. Journal of Food Protection, v. 68, n. 9, p. 1903-1906, 2005.

ROUCOURT, J.; SEELIGER, H. P. R. Distribution des especes du genre Listeria. Zentralbl. Bakteriologie, Mikrobiologie und Hygiene, v. 259, n. 3, p. 317-330, 1985.

RYSER, E. T.; DONNELLY, C. W. Listeria. In: DOWNES, F. P.; ITO, K. Compendium of methods for the microbiological examination of foods. 4 ed. Washington: APHA, 2001. cap. 36, p. 343-363.

RYSER, E. T.; MARTH, E. H. Listeria, listeriosis, and food safety. New York: Marcel Dekker, 1999. 738 p.

UHITIL, S. et al. Prevalence of Listeria monocytogenes and the other Listeria spp. in cakes in Croatia. Food Control, v. 15, n. 3, p. 213-216, 2004.

VITAS, A. I.; AGUADO, V.; GARCIA-JALON, I. Occurrence of Listeria monocytogenes in fresh and processed foods in Navarra (Spain). International Journal of Food Microbiology, v. 90, n. 3, p. 349-356, 2004.

WHYTE, P. et al. The effect of sampling time on the levels of microorganisms recovered from broiler carcasses in a commercial slaughter plant. Food Microbiology, v. 21, n. 21, p. 59-65, 2004. 